\title{
Surface Roughness and Surface Topography of Inconel 718 in Powder Mixed Dielectric Electrical Discharge Machining (PMEDM)
}

\author{
Said Ahmad', Mohd Amri Lajis ${ }^{2}$, Reazul Haq Abdul Haq ${ }^{2}$, Ahmad Mubarak \\ Tajul Arifin ${ }^{2}$, Mohd Nasrull Abdol Rahman ${ }^{2}$, Ho Fu Haw ${ }^{2}$, Haslina Abdullah', \\ Mohd Fahrul Hassan ${ }^{2}$
}

\author{
${ }^{1}$ Precision Machining Research Center (PREMACH), Faculty of Mechanical and Manufacturing Engineering, \\ Universiti Tun Hussein Onn Malaysia, Parit Raja 86400, Johor, Malaysia \\ ${ }^{2}$ Faculty of Mechanical and Manufacturing Engineering, Universiti Tun Hussein Onn Malaysia, Parit Raja 86400, \\ Johor, Malaysia
}

Received 28 June 2011; accepted 5 August 2011, available online 24 August 2011

\begin{abstract}
In high speed EDM, maximum material removal rate (MRR) is a desirable to increase productivity rate and reducing production cost to the need of industry. However, the surface finish of the machined surface also cannot be neglected since it related to product quality and safety factor especially when to cut difficult to machine material such Inconel 718, which is widely used in aerospace industry. Surface roughness as one of the surface integrity criteria was choose as a response in this research. High discharge current from $20 \mathrm{~A}$ to $40 \mathrm{~A}$, longer pulse on-time (pulse duration) from $200 \mu$ s to $400 \mu$ s and the different concentration of the nano Alumina powder were selected as the main parameters, respectively. The effect of powder mixed dielectric in EDM performance in terms of surface roughness was evaluated. The dielectric circulating system known as High Performance Electrical Discharge Machine (HPEDM) was attached to the conventional EDM machine to run the experiments involving powder mixed dielectric. The experiment results shows that, the highest peak current deteriorated the surface roughness. The surface roughness, $\mathrm{R}_{\mathrm{a}}$ was increased with the increasing of the peak current. The result also shows that an increasing of the pulse duration the surface roughness was slightly improved. It is observed that, the value of $\mathrm{R}_{\mathrm{a}}$ was closely related to the surface topography characteristic of the machined surfaces and directly depends on the applied discharge energy. There is no improvement in surface roughness when powder additive was mixed in a dielectric fluid. The lowest and the highest $\mathrm{R}_{\mathrm{a}}$ value achieved is $8.62 \mu \mathrm{m}$ and $21.69 \mu \mathrm{m}$, respectively.
\end{abstract}

Keywords: Powder mixed EDM, Inconel 718, Surface roughness, Surface topography

\section{Introduction}

Since there is a limitation to use a conventional machining to cut hard materials, non-conventional machining such as electrical discharge machining (EDM) is one of the preferred techniques in dealing with these materials such Inconel 718. EDM is known as a mostly used to facilitate complex machining problems in difficult to cut materials especially, for complicated geometric cutting and precision [1-3]. However, it is such a long time consuming of machining process that related to time and cost was almost the top issue to the manufacturing industries. Among other issues that are considered to be a problematic to EDM machine operators are, the difficulty of getting good surface roughness when using high discharge current. As the eroded of workpiece occur through sparking, the debris accumulation in the machining area usually resulting of poor EDM quality. That resulted not only in poor machining stability, but also deteriorated to the machined surface [4]. Moreover, when machining difficult to cut material such Inconel 718 , not only material removal is only priority, for safety critical industries such as aerospace, surface integrity is among significant criteria for the components submitted to high thermal and mechanical loads during their application [5]. Thus, it is highly needed to enhance the speed of machining which leads to higher productivity and to improve surface finish due to safety concern especially in the aerospace industry. Currently, there are many inventions in monitoring and developing an EDM process that have not been patented. Usually, the patent is in the area of EDM system, and only few of them are outside the EDM system, for example by using powder mixed dielectric in EDM processes, which is proven to increase the machining efficiency of EDM [6-8]. It was found that by using powder mixed dielectric in EDM could improve the surface finish and enhance material removal rate as well [9]. With improvement of fuzzy logic, better power supplies, robotic handling, and $\mathrm{CNC}$ orbiting of electrodes and workpieces, the efficiency of 
die-sink EDM have increased [10]. If the fundamental issues of the powder mixed dielectric can be explored and utilized, it capable to further reduce the machining costs related with EDM. The quality of an EDM product is not only evaluated on machinability aspect but also on its surface integrity (SI) such surface roughness, $\mathrm{R}_{\mathrm{a}}$. Thus, for this research, the complexity of this process, especially from the effects of the powder mixed dielectric in relation with higher discharge current and pulse on time to the surface roughness and surface topography is keen to be investigated.

\section{Research Procedure}

Inconel 718 was selected as a workpiece material. Its outstanding high temperature strength due to its very low thermal conductivity create difficulties during machining. Inconel are widely applied for the hottest parts in aircraft and thermo-reactor plant. Before conducting the experiment, the top surface of workpiece, was flattened by grinding machine. The Copper Tungsten $(\mathrm{CuW})$ with $10 \mathrm{~mm}$ of diameter was selected as an electrode. $\mathrm{CuW}$ is produced through powder metallurgy process. The combination of high electrical conductivity of Copper with high melting point of Tungsten, creates $\mathrm{CuW}$ electrode with very good wear properties

The experiments were run on a conventional Diesinking EDM machine, Sodick AQ55L with positive electrode polarity. Kerosene was selected as a dielectric medium with three powder concentration, $\mathrm{C}_{\mathrm{p}}$ conditions which are, without powder mixed, $\mathrm{C}_{\mathrm{p}}=0 \mathrm{~g} / \mathrm{l}$, with $\mathrm{C}_{\mathrm{p}}=2 \mathrm{~g} / \mathrm{l}$ and $\mathrm{C}_{\mathrm{p}}=4 \mathrm{~g} / \mathrm{l}$, respectively. $99.5 \%$ purity of the nano Alumina $\left(\mathrm{Al}_{2} \mathrm{O}_{3}\right)$ powder with an average particle size of $45 \mathrm{~nm}$ was selected as a powder mixed in a dielectric fluid.

To run the experiments with powder mixed dielectric, a dielectric fluid circulating device called high performance electrical discharge machining (HPEDM) as shown on Fig 1 are connected on the CNC Sodick EDM. The device built in with its own controller, working tank, pump and filters and functioning as 'plug and play' to the conventional EDM machine. The powder mixed will be poured into the kerosene of the HPEDM working tank before running the experiment. The EDM parameters and experimental conditions are stated in Table 1.

Average surface roughness, $R_{a}$ of the machined surface are measured using Mitutoyo SJ-400 Surface Roughness Tester. The measurement of surface roughness through surface irregularities are detected with reference to the guide on the drive unit, it can measure waviness and finely stepped features. The cut off length for each specimen measurement in this research is $0.8 \mathrm{~mm}$ and traverse length is $6.4 \mathrm{~mm}$. The value of $R_{a}$ is closely related to the surface topography characteristic of the machined surfaces.

For this study, the surface topography of the machined surface have been observed using Scanning Electron Microscope (SEM). The study of surface topography reflects changes on the exterior surface of a material, and includes things like smoothness, globules, nodules and craters formation after machining process.
Internal features address changes just below the outer surface, such as deformation and changes in strength or hardness. It not include internal changes deep within the base of a material, but rather in the layer just below the surface.

The results of experiment were obtained from a series of full factorial which overall trials of 27. Each sample was evaluated in terms of the surface roughness and surface topography of the machined samples. Then the comparison of performance is made between the conventional EDM and with the powder mixed dielectric EDM (PMEDM).

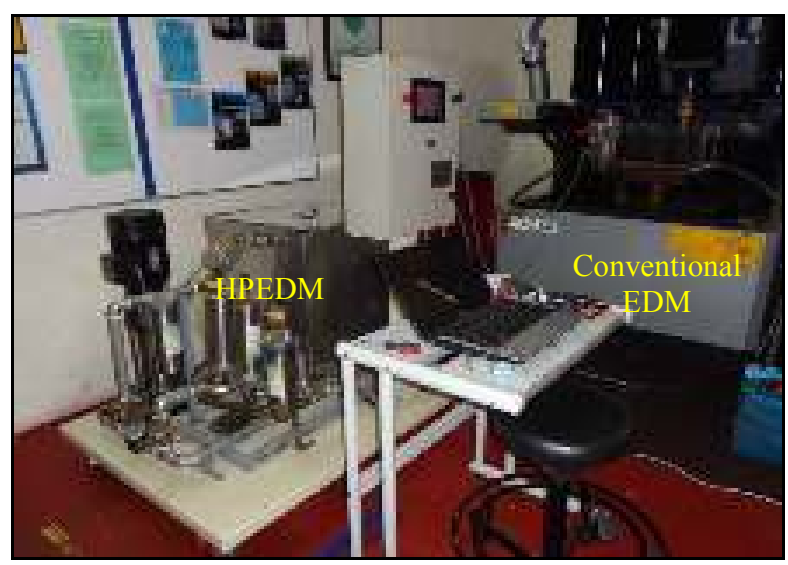

Fig 1 HPEDM device

Table 1 Experimental conditions

\begin{tabular}{ll}
\hline \multicolumn{1}{c}{ Parameters } & \multicolumn{1}{c}{ Levels } \\
\hline Discharge current, $\mathrm{I}_{\mathrm{p}}$ & $20 \mathrm{~A}, 30 \mathrm{~A}, 40 \mathrm{~A}$ \\
Pulse on time, $\mathrm{t}_{\text {on }}$ & $200 \mu \mathrm{s}, 300 \mu \mathrm{s}, 400 \mu \mathrm{s}$ \\
Pulse off time, $\mathrm{t}_{\text {off }}$ & Based on $80 \%$ duty cycle \\
Powder concentration, $\mathrm{C}_{\mathrm{p}}$ & $0 \mathrm{~g} / \mathrm{l}, 2 \mathrm{~g} / \mathrm{l}, 4 \mathrm{~g} / \mathrm{l}$ \\
Voltage, $\mathrm{V}$ & $120 \mathrm{~V}$ \\
Electrode polarity & Positive \\
Dielectric medium & Kerosene \\
Cutting depth & $3 \mathrm{~mm}$ \\
\hline
\end{tabular}

\section{Results and Discussion}

The surface roughness, $\mathrm{R}_{\mathrm{a}}$ was measured with three measurements on each sample and the average of roughness was calculated. Fig 2 presents the graph of the $\mathrm{R}_{\mathrm{a}}$. Referring in Fig 2(a), when EDM machining of Inconel 718 without powder concentration $\left(C_{p}=0 g / 1\right)$, the $\mathrm{R}_{\mathrm{a}}$ was increased with the increasing of discharge current, $\mathrm{I}_{\mathrm{p}}$ at all pulse on-time (pulse duration), $\mathrm{t}_{\mathrm{on}}$ level. At $\mathrm{t}_{\mathrm{on}}=200 \mu \mathrm{s}$, the $\mathrm{R}_{\mathrm{a}}$ was increased from $8.62 \mu \mathrm{m}$ at $\mathrm{I}_{\mathrm{p}}=20 \mathrm{~A}$ to $14.88 \mu \mathrm{m}$ at $\mathrm{I}_{\mathrm{p}}=40 \mathrm{~A}$. This is due to the spark intensity generated is high during the higher level of $\mathrm{I}_{\mathrm{p}}$, formed a large and wide crater depth on the surface of the work piece [11], therefore, $\mathrm{R}_{\mathrm{a}}$ was increased. The similar trend of graph pattern also can be observed when $t_{\text {on }}=300 \mu$ s and $\mathrm{t}_{\mathrm{on}}=400 \mu \mathrm{s}$ were used, the $\mathrm{R}_{\mathrm{a}}$ was increased with the increment of $I_{p}$ value.

The effect of pulse on-time, $t_{\text {on }}$ on the $R_{a}$ also significant. Normally, an increase in $t_{\text {on }}$ results in a proportional increase in spark intensity and can cause the melting boundary becomes deeper and wider, and hence 
increases the surface roughness [12-13]. However, due to longer heat generated on higher $t_{o n}$, an overlapping of craters boundary may be occurred during the resolidified of molten metal which is covering up the craters surface and produce more flatten crater. Thus, $R_{a}$ value was decreased with increasing of $t_{\text {on }}$ at all levels of $I_{p}$. Then, the existence of powder mixed in dielectric medium promotes an increase of $R_{a}$. From the Fig 2(b), the $R_{a}$ increased when $C_{p}=2 g / 1$ was suspended in the dielectric fluid in comparison to $\mathrm{C}_{\mathrm{p}}=0 \mathrm{~g} / \mathrm{l}$. At $\mathrm{t}_{\mathrm{on}}=200 \mu \mathrm{s}$, the $\mathrm{R}_{\mathrm{a}}$ was increased from $14.28 \mu \mathrm{m}$ to $21.56 \mu \mathrm{m}$ with increasing of $\mathrm{I}_{p}$ from $20 \mathrm{~A}$ to $40 \mathrm{~A}$. The increment trend of $\mathrm{R}_{\mathrm{a}}$ value with increasing of $I_{p}$ also can be seen at $t_{o n}=300 \mu \mathrm{s}$ and $\mathrm{t}_{\mathrm{on}}=400 \mu \mathrm{s}$.

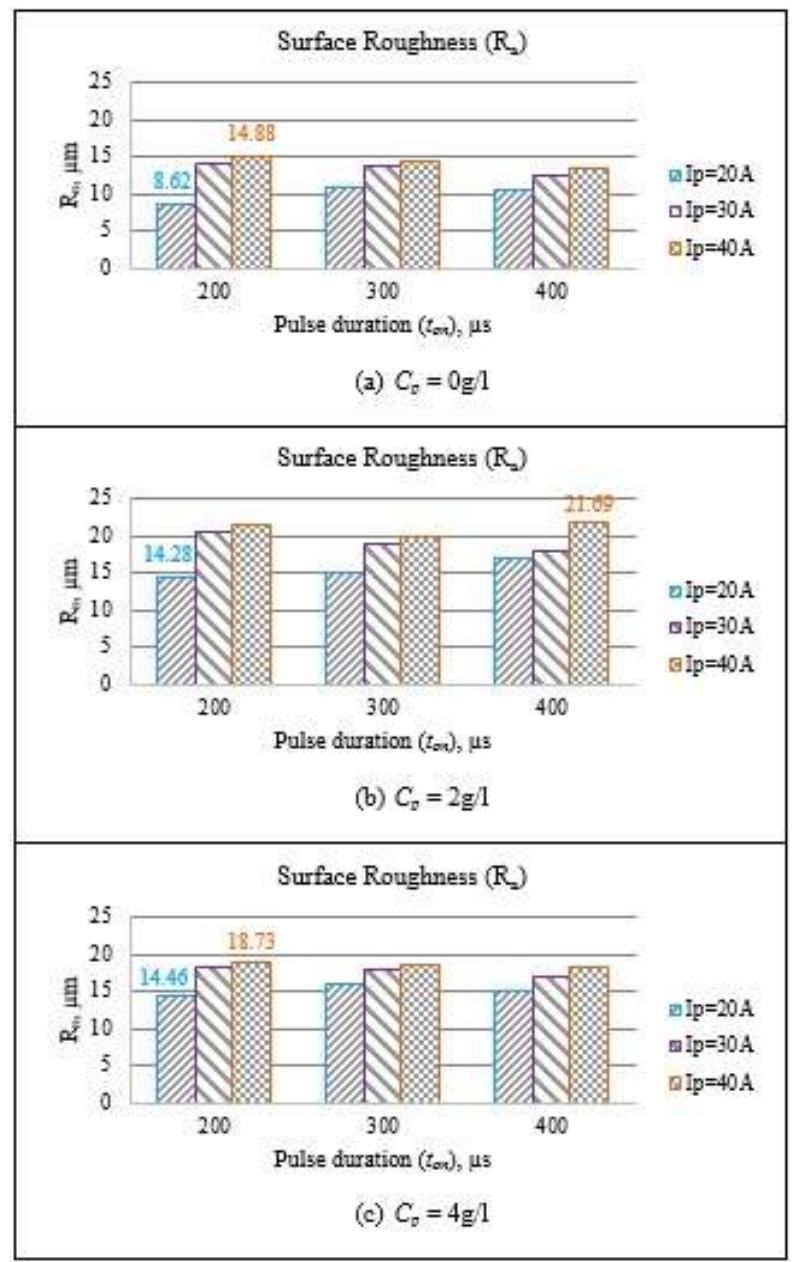

Fig 2 Effect of discharge current $\left(\mathrm{I}_{\mathrm{p}}\right)$ and pulse on-time $\left(\mathrm{t}_{\mathrm{on}}\right)$ on surface roughness at a different powder concentration [(a) $C_{p}=0 g / 1$, (b) $C_{p}=2 g / 1$ and (c) $\left.C_{p}=4 g / 1\right]$

It is noticeable that, the $R_{a}$ at the highest $C_{p}=4 g / 1$ applied is even severe to the observed for conventional dielectric as shown in Fig 2(c). This is because of the high discharge current supplied together with the presence of excessive particles of nano Alumina powder clog the discharge passage causes the frequent occurrence of short-circuiting and unstable condition that can be stated out as one of the reasons for the formation of wide and deep valleys [14-16]. The increase of the surface roughness and surface heterogeneity were contributed by these irregularities. Thus, the observation suggested that, the highest level of $I_{p}$ and shortest duration of $t_{o n}$ when EDM machining employing powder mixed dielectric will create the worst $R_{a}$. The lowest $R_{a}$ value is $8.62 \mu \mathrm{m}$ was achieved at $I_{p}=20 A, t_{o n}=400 \mu s$ and $C_{p}=0 g / 1$. Then, the highest $R_{a}$ value is $21.69 \mu \mathrm{m}$ obtained at $I_{p}=40 \mathrm{~A}$, $\mathrm{t}_{\mathrm{on}}=400 \mu \mathrm{s}$ and $\mathrm{C}_{\mathrm{p}}=2 \mathrm{~g} / \mathrm{l}$. Thus, for this study, conventional EDM with the lowest parameters setting is the best option if there is a need for good surface finish.

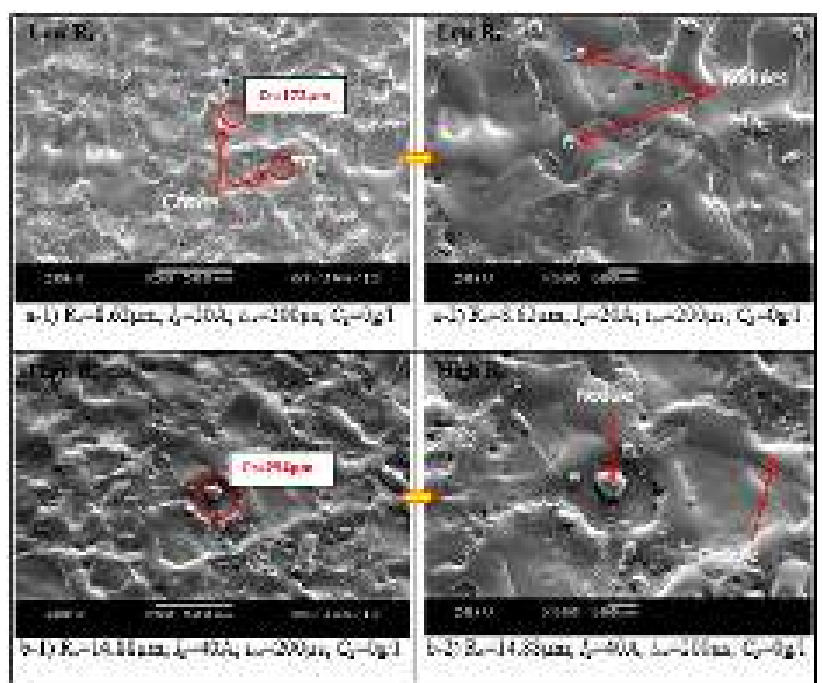

Fig 3 Surface topography at a $\mathrm{C}_{\mathrm{p}}=0 \mathrm{~g} / \mathrm{l}$ with different magnification according to [a) Low $R_{a}$ and b) High $R_{a}$ ]

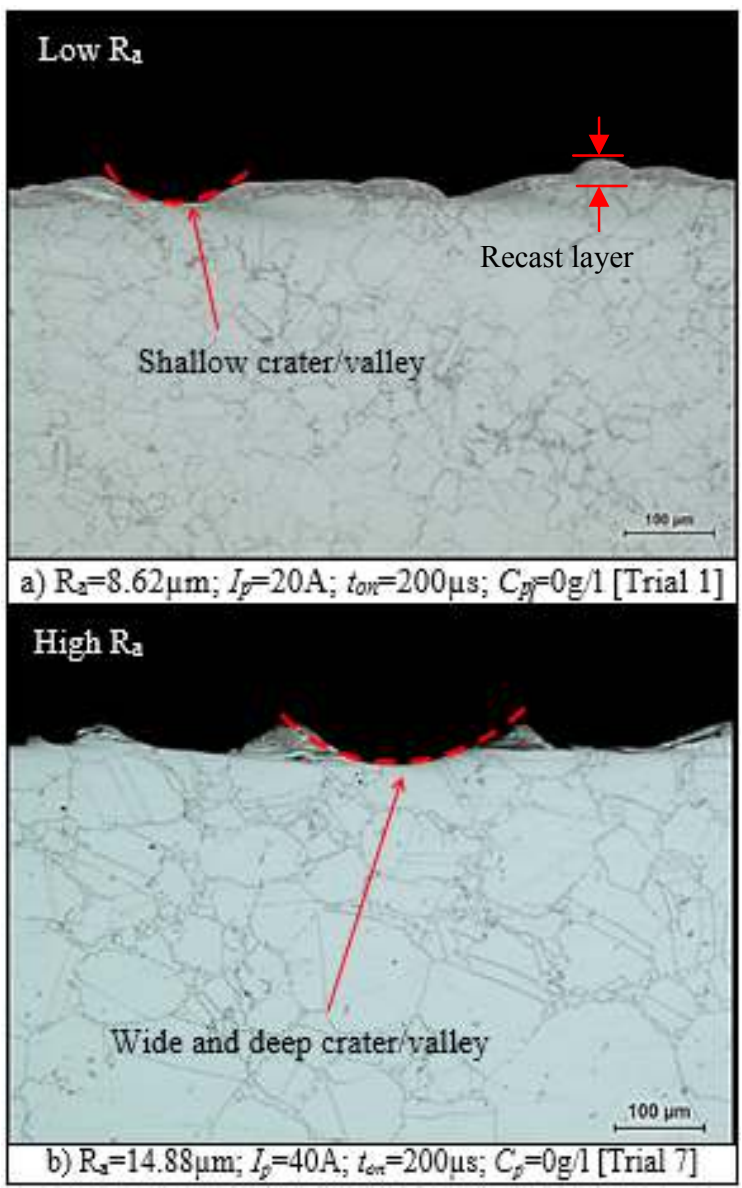


Fig 4 Cross section on the machined workpiece at a $\mathrm{C}_{\mathrm{p}}=0 \mathrm{~g} / \mathrm{l}$ according to [a) Low $\mathrm{R}_{\mathrm{a}}$ and $\mathrm{b}$ ) High $\mathrm{R}_{\mathrm{a}}$ ]

The value of $R_{a}$ is closely related to the surface topography characteristic of the machined surface. Fig 3 shows the surface topography on the machined surface according to low and high $\mathrm{R}_{\mathrm{a}}$ at $\mathrm{C}_{\mathrm{p}}=0 \mathrm{~g} / \mathrm{l}$ with different magnification. As we can see from Fig 3(a), the size of craters for the low $\mathrm{R}_{\mathrm{a}}$ is smaller in comparison to at high $\mathrm{R}_{\mathrm{a}}$ (Fig 3(b)). An existence of nodules also noticeable on the machined surface. This condition occurred due to insufficient time for flushing to remove the molten metal during pulse interval, caused the reattachment of molten metal also known as nodules on the machined surfaces. The size of nodules at high $\mathrm{R}_{\mathrm{a}}$ is bigger than the size of nodules at low $R_{a}$. The craters/valley formation at low $R_{a}$ is also shallow, but at high $R_{a}$, the craters were wide and deep as shows in Fig 4. Those conditions has proved that at high $I_{p}$, the machined surface will be deteriorated and contributed to the high $\mathrm{R}_{\mathrm{a}}$ value.

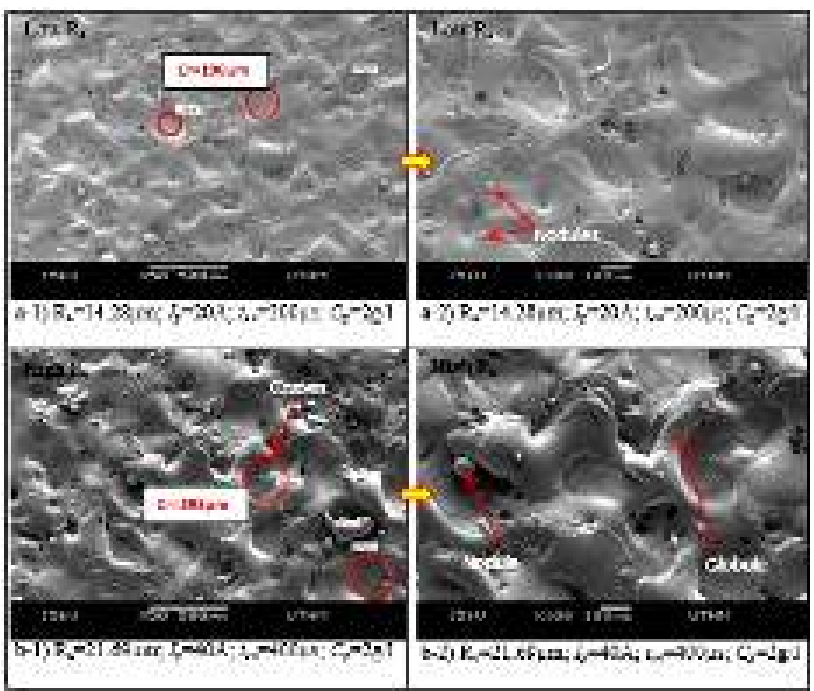

Fig 5 Surface topography of Inconel 718 at a $\mathrm{C}_{\mathrm{p}}=2 \mathrm{~g} / 1$ with different magnification according to [a) Low $\mathrm{R}_{\mathrm{a}}$ and b) High $R_{a}$ ]

Based on Fig 5, the topography of the machined surface when $\mathrm{C}_{\mathrm{p}}=2 \mathrm{~g} / \mathrm{l}$ of powder mixed was applied can be observed. At high $R_{a}$ as indicated in Fig $5(b)$, the surface looks rough with the existence of bigger nodules and size of craters in comparison to at low $\mathrm{R}_{\mathrm{a}}$ as shows in Fig 5(a). Referring Fig 6, the deep and wide of crater/valley formation also can be noticed at high $R_{a}$ value.

Then, at the highest $\mathrm{C}_{\mathrm{p}}=4 \mathrm{~g} / 1$ as shows in Fig 7 and Fig 8 , the similar topography condition can be observed as previous image. The size of craters is small and shallow on the machined surface at low $\mathrm{R}_{\mathrm{a}}$ condition, but conversely, the big and deep in size of craters were formed on the surface at high $\mathrm{R}_{\mathrm{a}}$ condition. Thus, it can be expected that, at high $\mathrm{I}_{\mathrm{p}}$ with a powder concentration in the dielectric fluid it will cost to the high roughness of the machined surface.

Based on the $R_{a}$ analysis, it is clear that higher $I_{p}$ and longer $t_{o n}$ causes a worse surface finish. A good surface finish can be obtained by setting at a low $I_{p}$ and low $t_{\text {on }}$, of the machining parameters respectively, but this approach will increasing the machining time and hence lower productivity.

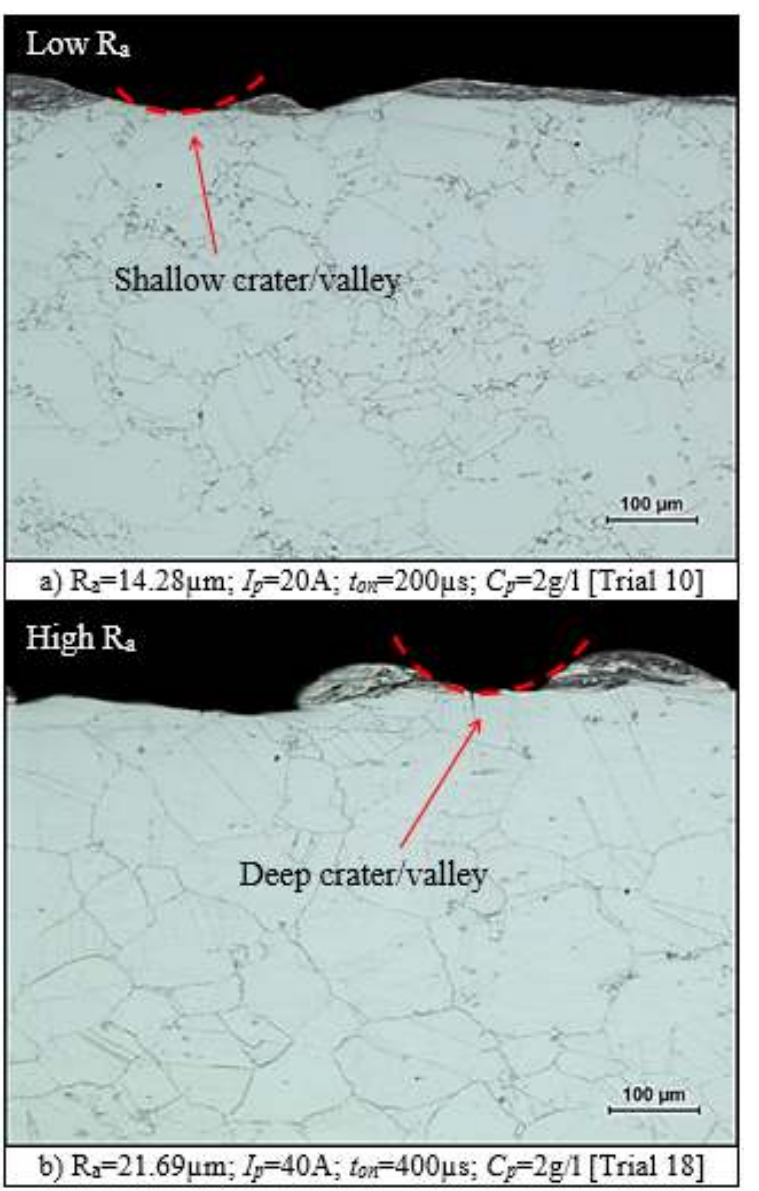

Fig 6 Cross section on the machined workpiece at a $\mathrm{C}_{\mathrm{p}}=2 \mathrm{~g} / \mathrm{l}$ according to [a) Low $\mathrm{R}_{\mathrm{a}}$ and b) High $\mathrm{R}_{\mathrm{a}}$ ]

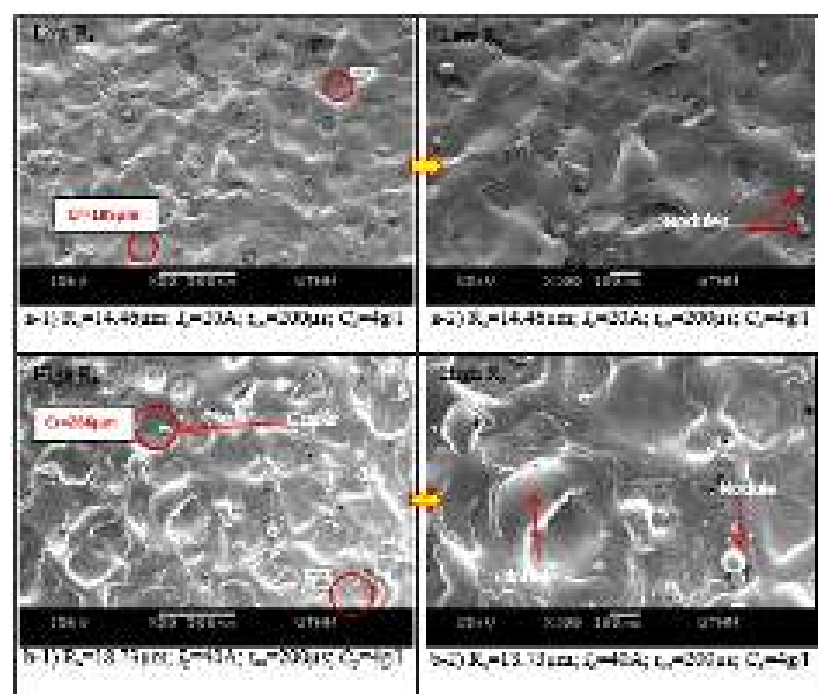

Fig 7 Surface topography at a $\mathrm{C}_{\mathrm{p}}=4 \mathrm{~g} / \mathrm{l}$ with different magnification according to [a) Low $\mathrm{R}_{\mathrm{a}}$ and b) High $\mathrm{R}_{\mathrm{a}}$ ]

The $R_{a}$ increase when the discharge current had been increased. In other side, the introduction of powder mixed 
in the dielectric fluid will also increase the $R_{a}$ value. It shows that the discharge current gives a significant impact on $\mathrm{R}_{\mathrm{a}}$ and lower discharge current can produce the finer surface texture. It can also be observed that the effects of powder concentrations on $\mathrm{R}_{\mathrm{a}}$ are less influential in improving the $\mathrm{R}_{\mathrm{a}}$ value.

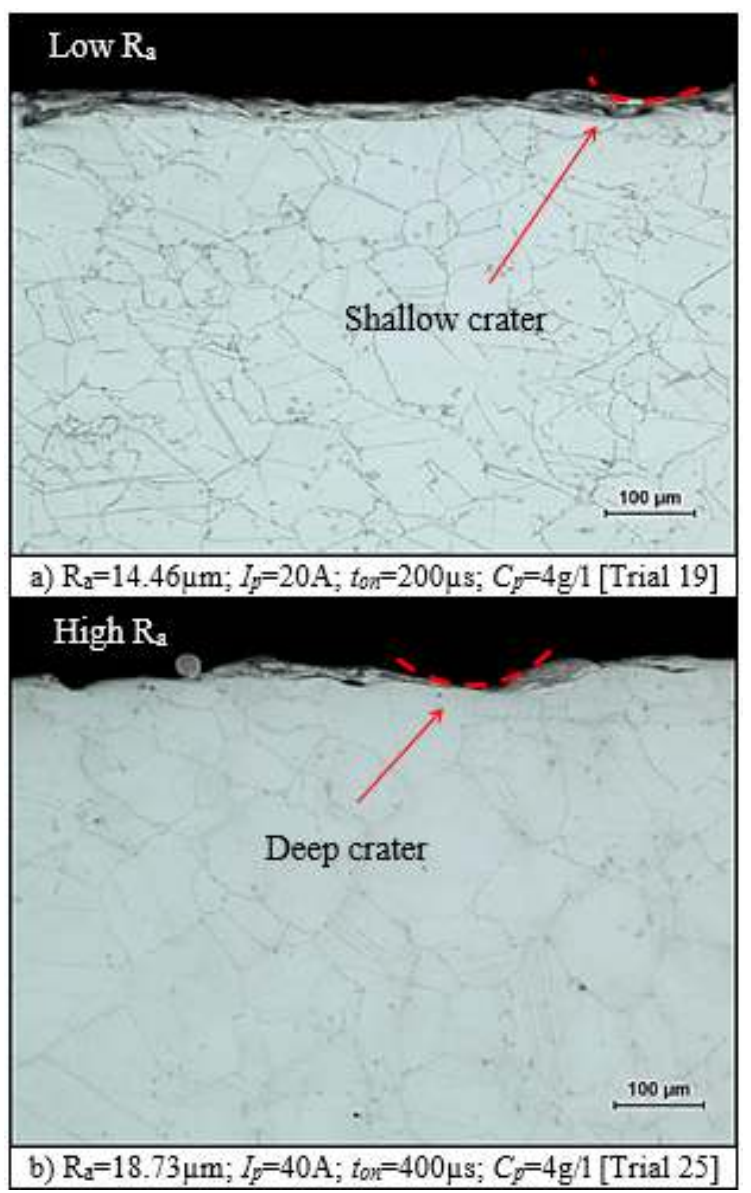

Fig 8 Cross section on the machined workpiece at $\mathrm{C}_{\mathrm{p}}=4 \mathrm{~g} / \mathrm{l}$ according to [a) Low $\mathrm{R}_{\mathrm{a}}$ and b) High $\mathrm{R}_{\mathrm{a}}$ ]

\section{Conclusion}

In EDM machining, the highest MRR with the lowest surface roughness is very desirable but usually the result is contradicted between both responses. When high MRR was achieved, the severe condition of surface roughness is expected. The highest peak current is not recommended for surface roughness. The surface roughness will increase when the increasing of the peak current. However, with increasing the pulse duration the surface roughness will decrease and there is no improvement in surface roughness when powder additive was mixed in a dielectric fluid. The lowest $R_{a}$ value is $8.62 \mu \mathrm{m}$ obtained at $I_{p}=20 A, t_{o n}=200 \mu$ s and $C_{p}=0 g / 1$. Then, the highest $R_{a}$ is $21.69 \mu \mathrm{m}$ achieved at $\mathrm{I}_{\mathrm{p}}=40 \mathrm{~A}, \mathrm{t}_{\mathrm{on}}=400 \mu \mathrm{s}$ and $\mathrm{C}_{\mathrm{p}}=2 \mathrm{~g} / \mathrm{l}$, respectively.

\section{Acknowledgment}

The authors would like to thank the Universiti Tun Hussein Onn Malaysia for financial support and providing facilities of research.

\section{References}

[1] Sulaiman, A., Ahsan, A. K., Qasim, S., and Mohamed, K. Temperature Distribution in Copper Electrode during Electrical Discharge Machining Process. International Journal of Integrated Engineering, Volume 9, (2017), pp. 39-43.

[2] Beri, N., Maheshwari, S., Sharma, C., and Kumar, A. Surface quality modification using powder metallurgy processed $\mathrm{CuW}$ electrode during electrical discharge machining of Inconel 718. Procedia Material Science, Volume 2, (2014), pp. 167-171.

[3] Helmi, M. H., Azuddin, M., and Abdullah, W. Investigation of Surface Roughness and Material Removal Rate (MRR) on Tool Steel Using Brass and Copper Electrode for Electrical Discharge Grinding (EDG) Process. International Journal of Integrated Engineering, Volume 1, (2009), pp. 3139

[4] Hsue, A. W. J., and Chih, H. C. Control strategy for high speed electrical discharge machining (diesinking EDM) equipped with linear motors. Advanced Intelligent Mechatronics, (2009). IEEE/ASME

[5] Dudzinski, D., Devillez, A., Moufki, A., Larrouquère, D., Zerrouki, V., and Vigneau, J. A review of developments towards dry and high speed machining of Inconel 718 alloy. International Journal of Machine Tools and Manufacture, Volume 44, (2004), pp. 439-456.

[6] Marafona J. Black layer characterisation and electrode wear ratio in electrical discharge machining (EDM). Journal of Material Processing. Technology, Volume 184, (2007), pp. 27-31.

[7] Kumar, A., Maheshwari, S., Sharma, C., and Beri, N. Analysis of Machining Characteristics in Additive Mixed Electric Discharge Machining of Nickel-Based Super Alloy Inconel 718. Materials and Manufacturing Processes, Volume 26, (2011), pp. 1011-1018.

[8] Tzeng, Y.F. Development of a flexible high-speed EDM technology with geometrical transform optimization. Journal of Materials Processing Technology, Volume 203, (2008), pp. 355-364.

[9] Kansal, H. K., Singh, S., and Kumar, P. Technology and research developments in powder mixed electric discharge machining (PMEDM). Journal of Materials Processing Technology, Volume 184, (2007), pp. 32-41.

[10] Prihandana, G., Mahardika, M., Hamdi, M., Wong, Y., and Mitsui, K. Accuracy improvement in nanographite powder-suspended dielectric fluid for micro-electrical discharge machining processes. International Journal of Advanced Manufacturing Technology, Volume 56, (2011), pp. 143-149.

[11] Sommer, C. Non-Traditional Machining Machining Handbook. Advance Publishing Inc, Houston. Texas, (2009) pp. 117-158. 
[12] Klocke, F., Schneider, S., Ehle, L., Meyer, H., Hensgen, L., and, Klink, A. Investigations on surface integrity of heat treated $42 \mathrm{CrMo} 4$ (AISI 4140) processed by sinking EDM. Procedia CIRP, Volume 42, (2016), pp. $580-585$

[13] Kang, S., and Kim, D. 2003. Investigation of EDM characteristics of nickel-based heat resistant alloy. Journal of Mechanical Science and Technology. Vol.17(10),pp. 1475-1484.

[14] Patel, K. M., Pandey, P. M., and Venkateswara, R. P. Surface integrity and material removal mechanisms associated with the EDM of Al2O3 ceramic composite. International Journal of
Refractory Metals and Hard Materials, Volume 27, (2009), pp. 892-899.

[15] Toshimitsu, R., Okada, A., Kitada, R., and Okamoto $\mathrm{Y}$. Improvement in surface characteristics by EDM with chromium powder mixed fluid. Procedia CIRP, Volume 42 (2016), pp. $231-235$.

[16] Pecas, P., and Henriques, E. Effect of the powder concentration and dielectric flow in the surface morphology in electrical discharge machining with powder-mixed dielectric (PMD-EDM). International Journal of Advanced Manufacturing Technology, Volume 37, (2008), pp. 1120-1132. 